\title{
Relações raciais no Brasil: colonialidade, dependência e diáspora
}

\section{Race relations in Brazil: coloniality, dependency and diaspora}

\section{Leonardo Ortegal}

Resumo: Este artigo discute as relações raciais no Brasil, numa perspectiva crítica ao conhecido equívoco teórico de que o racismo é meramente um subproduto das desigualdades de classe. Discute também a teoria marxista da dependência e a decolonialidade, de modo que o exercício de aproximação dessas teorias demonstrou que a TMD e a decolonialidade são ferramentas teóricas convergentes, dotadas de grande relevância para se compreender e intervir na realidade brasileira de desigualdade social e racial.

Palavras-chave: Raça. Racismo. Decolonialidade. Teoria marxista da dependência. Genocídio. Diáspora.
Abstract: This article discusses race relations in Brazil, in a critical perspective to the wellknown theoretical misconception that racism is merely a by-product of class inequalities. It also discusses the Marxist Theory of Dependency and Decoloniality, so that the exercise of approximation of these theories demonstrated that TMD and Decoloniality are convergent theoretical tools, endowed with great relevance to understand and intervene in the Brazilian reality of social and racial inequality.

Keywords: Race. Racism. Decoloniality. Marxist theory of dependency. Genocide. Diaspora.

\section{Introdução}

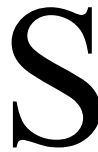

abemos que qualquer esforço de compreensão da realidade brasileira a partir de sua história já revela indícios suficientes de que tal compreensão é impossível se tivermos como ferramentas apenas referenciais teórico-metodológicos importados direto dos países hegemônicos. Isso nos leva a perceber que a compreensão das realidades dos países capitalistas dominantes não significa a compreensão das dinâmicas do capitalismo nos 
países subalternos. Foi diante desse fato que Rui Mauro Marini, Florestan Fernandes e outros se esforçaram para contestar o processo vigente nas ciências sociais dos países latino-americanos à época, em que se buscava compreender a realidade local a partir da utilização de referenciais europeus e estadunidenses de forma imediata, ou seja, sem compreender as particularidades da realidade brasileira ou da América Latina como um todo.

Essa não foi uma lacuna exclusiva das perspectivas positivistas, mas também de perspectivas críticas como o próprio marxismo, sempre que aplicado sem considerar as particularidades da realidade local. A proposta de uma teoria marxista da dependência busca compreender a realidade latino-americana não apenas de forma crítica, como também a partir de suas características próprias, sendo a dependência uma de suas características principais para essa perspectiva.

Essa, porém, não é a única tentativa teórica de compreender a realidade local considerando especificidades em relação à realidade dos países hegemônicos. O próprio fenômeno que desencadeia o pensamento equivocado de associação direta entre a realidade dos países hegemônicos a uma realidade universal é uma demonstração de que a nossa forma de compreender o mundo está marcada pelo que seria a colonialidade. É essa uma das principais assertivas da perspectiva ${ }^{1}$ decolonial, que se dedica a recuperar e produzir saberes a partir desses lugares e sujeitos que têm em comum as marcas da subalternização na era moderna. ${ }^{2}$ Essa abordagem decolonial lança uma nova luz sobre os processos que marcam o início da era moderna e sobre como eles, muitas vezes aparentemente encerrados no passado, estruturam as relações na contemporaneidade. $\mathrm{Na}$ verdade, mais do que simplesmente lançar uma nova luz, o projeto decolonial busca

1. Às vezes referida como projeto, às vezes como abordagem, entre outros termos, será aqui referida apenas como perspectiva para não confundir o/a leitor/a durante a exposição do texto.

2. O aprofundamento acerca da colonialidade como uma das chaves de compreensão do mundo nos últimos séculos é um esforço não apenas da abordagem decolonial, mas também de outras correntes de pensamento, como a pós-colonial, descolonial e outras, que partilham entre si semelhanças e diferenças. Neste texto, porém, a perspectiva análise é a abordagem decolonial. Sobre distinções entre essas perspectivas, conferir Bernardino-Costa e Grosfoguel, 2016. 
resgatar pensamentos e autores que já realizavam esse trabalho teórico e que, no entanto, não tiveram a devida importância em seu tempo e lugar, em razão dos próprios processos da colonialidade e da subalternização. Esses processos assujeitam não apenas países, continentes ou economias, mas também determinados indivíduos, a partir de suas marcas, idiomas, linguagens e outras características, num processo que ocorre não apenas do império para fora, como também do império para dentro (Bernardino-Costa e Grosfoguel, 2016). Nesse processo é possível, então, matizar as realidades nacionais muitas vezes tratadas de forma homogênea, de modo que os países dominantes se revelam marcados por desigualdades diversas. Isto significa que, além das desigualdades de classe, outros processos são responsáveis por desigualar e assujeitar determinados indivíduos e grupos, por meio da raça, ${ }^{3}$ da etnicidade, do gênero e outros.

Assim como na maioria dos países da América Latina, o Brasil, fundado enquanto Estado-nação a partir da colonização de países europeus, sobretudo de Portugal, teve como principal força de trabalho do país ao longo de seus cinco séculos de existência as pessoas trazidas à força do continente africano. Esse povo, que resistiu às mais diversas tentativas de aniquilação e que hoje é majoritário no território nacional, é denominado como população negra, e sua experiência no país é também compreendida por diversos intelectuais e ativistas negros como parte da diáspora africana. Essa diáspora não é uma experiência exclusiva dos negros brasileiros, mas é partilhada em diversas partes do mundo e, de modo especialmente semelhante, nos países da América Latina e do Caribe, unidos simbolicamente pelo Atlântico Negro. ${ }^{4}$ A ideia de diáspora possibilita perceber as proximidades entre experiências geograficamente distantes, ao mesmo tempo que permite compreender os distanciamentos entre experiências de vida entre os grupos populacionais que compõem uma mesma nação. É a compreensão da

3. Aqui, vale dizer, raça e etnia possuem, não um sentido biológico, mas sociológico, cuja amplitude inclui outros processos, como xenofobia, migração, religiosidade, idioma, sotaque, fenótipo, indumentária e outros.

4. Atlântico Negro é a metáfora utilizada por Paul Gilroy (2012) para este elo entre os países africanos e da Diáspora. 
diáspora e seus desdobramentos que permitem perceber as particularidades da experiência racializada das relações sociais, ainda que se esteja tratando de grupos pertencentes a uma mesma classe social ou a um mesmo extrato socioeconômico.

Um exemplo disso é o fenômeno dos homicídios na sociedade brasileira. Analisando os dados do Mapa da Violência (Waiselfisz, 2014), é possível observar que os homicídios estão concentrados em bairros de menor poder econômico e infraestrutura, nos quais vivem as classes trabalhadoras de média e baixa renda. Seria esperado, portanto, que os homicídios estivessem determinados unicamente por uma questão de classe. Todavia, dentre os jovens assassinados no Brasil, 70\% são negros, percentual muito acima da representação de jovens negros no país. Além disso, num período de dez anos, a taxa de homicídio de jovens negros sofreu um crescimento de $32 \%$, enquanto o percentual de jovens brancos diminuiu 32\% (Waiselfisz, 2014, p. 184).

Em razão de sua flagrante seletividade racial, esse fenômeno ficou conhecido como extermínio da juventude negra, e é um entre os exemplos que evidenciam a importância de se conhecer a experiência da diáspora negra para que se possa efetivamente compreender a realidade brasileira. Fica mais do que evidente também a necessidade de se compreender a dimensão racial dos fenômenos sociais da realidade brasileira, quando se entende que tanto os processos da colonialidade quanto os da diáspora são estruturados pela ideia de raça, isto é, de que a humanidade é constituída de diferentes grupos raciais.

Diante disso, tornam-se imprescindíveis os estudos sobre as ideias de dependência, colonialidade e diáspora, tendo raça como um dos pilares epistemológicos principais para se compreender a realidade brasileira em suas particularidades. ${ }^{5}$ Em razão de tal importância, este artigo se propõe a discutir cada uma delas, seguidas de algumas considerações finais acerca desse movimento de compreensão da realidade latino-americana e, mais especificamente, a brasileira, a partir de teorias diferentes entre si, mas que demonstram potencial de complementaridade, pois têm em comum o esforço

5. Sobre a categoria particularidade aqui utilizada, cf. Lukacs (1978). 
de compreender tal realidade não mais apenas a partir do universal, mas a partir de suas particularidades.

\section{Tensões raciais no processo de formação do Brasil}

Qualquer aproximação mais atenta em relação ao estudo da história brasileira é capaz de evidenciar o quanto as relações entre europeus, indígenas e africanos foram marcadas por distinções de cunho racial. Ora por argumentos espirituais, ora por argumentos biológicos e médicos, e até mesmo pelo senso comum senhorial, negros e indígenas eram classificados e reclassificados ao olhar do europeu de forma racializada, isto é, de forma a estabelecer distinções entre esses três grandes grupos, não apenas com um sentido de hierarquização, mas de definição do que era ou não considerado humano. ${ }^{6}$ Tal elemento é importante para compreender as relações sociais no Brasil, pois, em um mundo marcadamente antropocêntrico, caracterizar determinado grupo como não humano ou sub-humano resultava em total isenção moral para a exploração, escravização e extermínio desse grupo assim classificado. Isto está evidenciado nos mais diversos estudos da historiografia e da sociologia do Brasil e não teve seus efeitos suspensos "por decreto", como a promulgação da Lei Áurea ou da Proclamação da Independência.

Dessa forma, muito antes de as classes sociais capitalistas emergirem e passarem a exercer forte determinação sobre os processos de relações sociais na maior parte do mundo, era a raça o distintivo oficial entre os grupos sociais nas metrópoles e colônias. Entretanto, à medida que o capitalismo foi se consolidando como modo de produção tanto nos países europeus quanto nas Américas, difundiu-se também a ideia de que o racismo ia chegando ao fim, dada a associação direta entre racismo e escravidão, bem como em virtude da condição supostamente indistinta de trabalhador que o livre mercado oferecia a todos os que dependiam da própria força de trabalho. Sobretudo

6. Para um estudo aprofundado sobre a invenção do "ser negro", conferir Santos (2002). 
num país como o Brasil, no qual a convivência entre brancos e negros era supostamente pacífica, narrada principalmente por Gilberto Freyre ([1933] 1998) como um palco romântico da democracia racial $^{7}$ e da sublimação das diferenças, a ideia de que raça e racismo seriam dois componentes fundantes e fundamentais das desigualdades e violências da nova sociedade passou a dar lugar a explicações de caráter liberal, fundamentadas nas competências e no mérito individual, por um lado, no caráter de classe que se estabelecia, por outro.

O fato é que, no século XIX, o impulso capitalista causado pela Revolução Industrial e pela nova organização e divisão do trabalho que esta demandava coincide com os principais processos de abolição da escravidão racializada no Ocidente, sendo o Brasil considerado o país a realizá-la mais tardiamente, em 1888. As mudanças no modo de produção geradas pela Revolução Industrial se desdobram nos mais diversos aspectos da sociedade. Entre estes, as relações entre dominados e dominantes, de modo que a abolição do regime de trabalho escravista não foi somente atravessada por lutas sociais do povo negro ou por concepções ideológicas abolicionistas, mas também pelas transformações econômicas em curso, de modo que a própria Inglaterra, antes um dos principais países no processo de reprodução do trabalho escravo, passou a coibi-lo de forma incisiva, com o objetivo de consolidar o novo sistema econômico e social do qual era protagonista (Moura, 2014).

Nesse processo de transição do regime escravista para o capitalista, a mão de obra escravizada passa a ser substituída pela mão de obra livre e assalariada. Isso, porém, não significa dizer que o trabalhador que antes era escravizado foi absorvido como assalariado. Num sentido contrário, estudos como o de Sales dos Santos (1997) demonstram a intensificação da importação de mão de obra de países europeus, com vistas a substituir os trabalhadores negros, movidos pela ideologia racista do sucessivo branqueamento da população brasileira. É nesse contexto, então, que se formam no Brasil as classes sociais capitalistas. Num contexto de enfraquecimento

7. Sobre o conceito de democracia racial, conferir Guimarães (2002) e Bernardino (2002). 
progressivo do regime escravista, em que as elites econômicas e políticas do país se viam diante de um impasse em relação a quem seria o tipo ideal de ocupante dos postos de trabalho do novo modelo econômico.

A pesquisa realizada por Santos (1997) apresenta trechos de discursos e de jornais da época, nos quais se discutia abertamente a transição para o regime do mercado de trabalho livre. A opinião de maior força era a de que negros, além de não possuírem os requisitos necessários para suprir a nova demanda, eram indesejáveis para o futuro do país, cuja elite econômica e política desejava que se tornasse branco. O imigrante europeu era considerado superior ao indivíduo negro e ao asiático, embora estes tivessem os custos para a importação menores que os do europeu (Idem). Quanto ao imigrante asiático, a exemplo da malquista africanização resultante do regime escravista, o receio era o da "mongolização" do país (Idem). Quanto a isso, até mesmo o louvado político abolicionista Joaquim Nabuco falou a respeito, se manifestando contrário à imigração espontânea de africanos e asiáticos, ao mesmo tempo em que lamentava a expulsão dos holandeses da província de Pernambuco, a qual representava como deputado federal. Em um de seus discursos no Congresso Nacional, ${ }^{8}$ dizia Nabuco sobre a tentativa fracassada de colonização holandesa, que "nós tivemos talvez essa possibilidade de sermos uma nação maior do que somos, mas nem a imigração africana, nem a imigração mongólica me inspiram a mesma simpatia" (Nabuco, 1983, p. 185, apud Santos, 1997). Santos afirma que uma das razões para a defesa do abolicionismo feita por Nabuco se devia ao atraso que o trabalho escravo representava para a transição ao trabalho livre e à importação de mão de obra europeia: "Não se pode ter ao mesmo tempo trabalho livre e trabalho escravo, escravatura e imigração" (Nabuco, 1983, p. 183, apud Santos, 1997).

Episódios como esses são demonstrações de que as ideias de raça (e o racismo que lhes são inerentes) não se extinguiram no processo de transição do trabalho escravo para o trabalho livre. Pelo contrário, as mesmas ideias

8. Os discursos podem ser acessados na íntegra por meio da publicação Perfis parlamentares, n. 58: Joaquim Nabuco (2010), disponível no portal da Câmara dos Deputados. 
racistas que atribuíam superioridade e inferioridade a diferentes indivíduos por origem e fenótipo nos séculos da escravidão também pautaram e determinaram a constituição do trabalho livre e do capitalismo em território brasileiro. Neste breve panorama é possível perceber o quanto a história do Brasil é saturada de elementos que marcam sua constituição, como as relações de dependência em relação aos países capitalistas centrais, as relações de colonialidade operando tanto de fora para dentro do território como internamente, bem como a centralidade da diáspora no processo de construção do país.

Tudo isso, porém, não seria possível sem que a concepção de que a humanidade era dividida entre raças fosse amplamente aceita como verdade do ponto de vista científico. Ao longo do século XX, porém, essa tese vem a perder força, passando a ser combatida e sendo praticamente extinta dos discursos oficiais, sobretudo após a derrota nazista. Contudo, se por um lado as distinções de raça foram se esvaziando de sentido em seu fundamento biomédico, em seu sentido sociológico tais ideias passaram por um intenso processo de sofisticação, tornando-se extremamente importantes no processo de constituição do Brasil como Estado-nação com as profundas marcas de desigualdade, violência e privilégio que carrega ainda hoje. Portanto, faz-se necessário compreender de que forma a raça incide nas relações sociais brasileiras e de que forma as marcas da colonialidade e da dependência são por ela atravessadas.

\section{Raça e racismo no contexto brasileiro}

Apesar de possuírem características comuns nos mais diferentes países, as ideias de raça e a operação do racismo possuem peculiaridades que as diferenciam de um território para outro. Na realidade brasileira, a ausência de um regime de segregação como o apartheid e o Jim Crow estadunidense, favoreceu por muito tempo a ideia já referida de um paraíso racial, onde brancos e não brancos conviviam harmoniosamente após o fim da escravidão. Essa suposta realidade despertou o interesse da Organização das Nações Unidas e de outras instituições ligadas à pesquisa e fomentaram uma série 
de estudos, sobretudo durante as décadas de 1950 e 1960, com o intuito inicial de compreender os segredos por trás do êxito brasileiro em superar o racismo (Nogueira, 2007). O que acontece é que o resultado da grande maioria das pesquisas realizadas confirmou a existência de um racismo à brasileira, o que o movimento negro brasileiro já afirmava e enfrentava décadas antes. ${ }^{9}$ Comprovou-se, então, academicamente, a existência do racismo no Brasil, e entre suas principais características encontravam-se: a) o fato de estar mais associado à cor da pele e do fenótipo do que à origem racial de um indivíduo, que ficou conhecido como preconceito racial de marca, em oposição ao preconceito racial de origem (Idem), b) a capacidade de operar no cotidiano e produzir apartação sem realizá-lo explicitamente, o que ficou conhecido também como racismo cordial (Turra e Venturi, 1995), assim como c) a capacidade de operar sem explicitar aquele que o opera, apelidado de racismo sem racistas, caracterizado a partir da pesquisa realizada pelo Instituto DataFolha (Idem), em que 89\% dos entrevistados consideravam existir racismo no país, enquanto apenas $10 \%$ admitiam ser racistas.

Orientados por forte inspiração do marxismo vigente nesse período, os estudos mais difundidos em relação à questão racial, de autores como Florestan Fernandes, Carlos Hasenbalg, Octavio Ianni e outros, eram geralmente voltados para compreender o negro nesse novo modo de produção: o capitalismo. Durante a segunda metade do século XIX foi construída uma noção, que até hoje possui forte incidência, de que, diferentemente dos séculos anteriores em que vigorava a escravidão e as ideologias racialistas falidas, o racismo no capitalismo estaria subordinado à desigualdade de classe. Partindo-se de um pressuposto factualmente comprovado de que a maioria da população pobre era a população negra, desenvolveu-se politicamente a tese economicista de que o racismo poderia ser extinto resolvendo-se as desigualdades de classe.

O desenvolvimento dos estudos sobre raça, entretanto, vem demonstrando a multiplicidade de origens e efeitos das mais variadas expressões do

9. Meios de comunicação como, por exemplo, o jornal Quilombo, criado por Abdias do Nascimento, são de 1948 . 
racismo, que se retroalimentam continuamente e extrapolam as estruturas econômicas. Jurema Werneck, fundadora da ONG Criola e atual diretora da Anistia Internacional no Brasil, apresenta, baseada na concepção apresentada por Camara Jones a estrutura do racismo em três dimensões (Jones apud Werneck, 2016): 1) pessoal/internalizado, relacionado a sentimentos e condutas do próprio indivíduo para consigo e a aceitação individual de padrões e estigmas racistas, 2) interpessoal, manifestado por meio de ações ou omissões presentes nas relações sociais, por meio das quais se expressam o preconceito e a discriminação, expressões mais conhecidas do racismo, geralmente significados pelo senso comum como o racismo em sua totalidade, 3) racismo institucional, também conhecido como racismo sistêmico, e que contempla ainda a perspectiva do racismo estrutural. Esta dimensão está associada a questões materiais e de acesso a poder. Sua complexidade está no fato de que geralmente não é possível identificar um indivíduo a operar esse tipo de racismo, que se encontra difuso nas dinâmicas institucionais e políticas, em processos históricos e na escassez de acesso à informação e outros recursos. Essas três dimensões, afirma Werneck, atuam de modo concomitante, "gerando sentimentos, pensamentos, condutas pessoais e interpessoais, atuando também sobre processos e políticas institucionais" (2016, p. 541).

O esquema apresentado por Werneck é didático e analítico, pois procura definir o racismo, este conceito muitas vezes difuso, em diferentes dimensões que são, na verdade, expressões de um mesmo fenômeno. A partir dessas dimensões, é possível compreender que as consequências do racismo não se resumem às questões econômicas. É uma forma de violência que agride o indivíduo também em seu subjetivo. Que elimina a história de um povo e que gera processos institucionalizados, mesmo que de maneira indireta, porém de extrema eficácia. É importante, todavia, frisar que, embora didático, esse esquema explicativo das dimensões do racismo não pode ser tomado desprovido de mediações, sob o risco de não conferir ao fenômeno do racismo a profundidade e a intensidade que possui. Nesse sentido, é importante acrescentar a esse fenômeno duas outras categorias: diáspora e genocídio. 
É a diáspora, mais precisamente a diáspora africana, a categoria responsável por reconectar o problema do racismo à sua formatação histórica na modernidade. Sem a compreensão dos flagelos sofridos pela população negra trazida à força para as colônias europeias, e de como esse histórico produz efeitos nos dias de hoje, tratar de racismo tende a ser mais um dos debates sobre as mazelas da sociedade capitalista do século XXI, aferíveis em números e curvas gráficas. $O$ conhecimento sobre a diáspora africana é o que possibilita recompor as dinâmicas de opressão nos países colonizados, extrapolando as geografias oficiais e complexificando o esquema socioeconômico tradicional, em que a opressão está diretamente relacionada à pobreza econômica. A compreensão da diáspora é que faz emergir o Atlântico Negro, expressão trazida por Paul Gilroy, que, entre outras contribuições, mostra que a experiência de um negro brasileiro pobre pode ser mais próxima à de um negro estadunidense rico do que a de um brasileiro branco, seja ele rico ou pobre. Essas conexões redescobertas por meio da identificação de "correntes marítimas" de unidade entre os países colonizados trazida pela identificação desse Attântico Negro possibilita a constituição de novas rotas, formas e motivos para a coletivização da população negra das Américas, como parte do caminho de reescrita de sua história nesses territórios, de suas experiências de preservação de valores, de resistência e de reexistência, mas também de opressão e genocídio.

O genocídio, mais precisamente o genocídio negro, é uma expressão que possui tanto um sentido denotativo quanto conotativo. No sentido denotativo está o movimento político e jurídico de classificar o conjunto de processos a que está submetida a população negra (no caso específico, a brasileira), como um crime de genocídio. Isto implica o reconhecimento de organismos internacionais e as penas e indenizações legalmente previstas para esse tipo de caso, como foi o genocídio do povo judeu pelo regime nazista (Flauzina, 2014). Em seu sentido conotativo, está o uso da categoria genocídio como capaz de elucidar as conexões entre as violências e violações perpetradas contra a população negra, tratadas, via de regra, pelo Estado e pelas políticas sociais como problemas isolados. Nesse sentido, a predominância de 
pessoas negras entre os casos de mortalidade materna, de evasão escolar e de encarceramento não são fenômenos independentes (Almeida, 2015). Estão essencialmente ligados por esse processo genocida, que é perverso, pelo fato de transcorrer ao longo dos séculos de existência do país, sem nunca ser enunciado enquanto tal, mas sempre como uma "coincidência" de tragédias (Ortegal, 2016).

É a categoria genocídio negro que traduz esse processo ativo, dotado de intencionalidade e racialmente determinado. É essa a categoria responsável por retirar a questão do racismo de seu local clássico, sobretudo no Brasil, de passividade, aleatoriedade, condicionado-a como subproduto das desigualdades de classe do capitalismo. Esse genocídio não pode ser compreendido sem que se compreenda também a diáspora negra, como categoria que dá ao racismo a profundidade histórica que este possui, desvelando os contínuos persistentes até hoje entre o que ocorreu no início do século XVI e o que acontece em pleno século XXI com a população negra. É o que complexifica as relações sociais no Brasil e que faz emergir outras referências para a composição dos processos de opressão, revelando o caráter racista nas composições intragênero, intraclasse e outras. Por ser uma categoria dual, diferentemente da categoria essencialmente negativa que é o genocídio, a diáspora traduz não apenas a violência do sequestro e do apagamento da identidade de um povo. Aponta também para, a partir da consciência dos processos de violência, as possibilidades de reconexões históricas e epistemológicas com aquilo que fora apartado no processo diaspórico, e, consequentemente, abre novas possibilidades para a reorganização desse povo oprimido e sua luta.

Com essa contribuição teórica trazida pelas categorias genocídio e diáspora, a categoria racismo adquire outro patamar de complexidade, profundidade e também centralidade no processo de compreensão da história e da realidade brasileira. Esse processo atravessa e é também atravessado pela colonialidade e pela dependência, categorias que intitulam duas escolas de pensamento que, por sua criticidade e relevância, serão aqui discutidas, num esforço introdutório de aproximação e interlocução entre elas. 


\section{Teorias críticas para a realidade brasileira: a perspectiva decolonial e a teoria do capitalismo dependente}

Assim como é equivocada a ideia aqui já discutida de que o racismo é meramente uma expressão ou um subproduto das desigualdades sociais capitalistas, ${ }^{10}$ é também insuficiente a tentativa de compreensão da dinâmica do racismo no Brasil ignorando a tarefa de situar as relações raciais na estrutura social e econômica em que estão inseridas. Esse esforço implica ir além do superficial. Ir além de se afirmar, por exemplo, que o país vive sob o regime capitalista, socioeconomicamente dividido entre classes desiguais, de modo que a parcela minoritária da população brasileira vive em condição de abundância patrimonial, enquanto a maior parte da população vive em condições de pobreza ou extrema pobreza. ${ }^{11}$ Informações como estas, embora verídicas, são apenas a expressão superficial da realidade social, que mantém ocultas as estruturas e dinâmicas que determinam e produzem tal realidade.

A hegemonia da produção de teorias e recomendações a respeito do desenvolvimento dos países dentro do modelo capitalista estão concentradas em agências internacionais, como o Banco Mundial e países dominantes, com destaque para os Estados Unidos (Burginski, 2016). Uma análise superficial e imediata poderia induzir a crer que a obediência às perspectivas e recomendações feitas pelas agências e países posicionados no topo do mundo capitalista levariam os países menos desenvolvidos a um patamar mais próximo ao daqueles em melhor situação. É justamente em contraposição a esse tipo de proposta que se levantam teorias como a chamada teoria marxista da dependência.

10. Diversos são os dados que evidenciam que raça e classe muitas vezes possuem incidências desagregadas. Além das taxas de homicídios entre jovens já mencionadas, a taxa de homicídios entre mulheres, no período de 2003 a 2013, aumentou $54,2 \%$ entre mulheres negras, enquanto reduziu $9,8 \%$ entre mulheres brancas (Waiselfisz, 2014).

11. O recente relatório da Oxfam Brasil (2017) apresenta dados importantes dessa realidade social do país. Esse panorama, no entanto, deve ser o ponto de partida de uma discussão mais ampla sobre a reprodução social no Brasil. Tratado como ponto de encerramento do assunto, o debate resta superficial, como recorrentemente tem sido. 
Desenvolvida a partir dos anos 1960, essa teoria dedica-se a compreender a condição dependente dos países periféricos como elemento da própria lógica de funcionamento da economia capitalista mundial (Carcanholo, 2013). Dentro dessa perspectiva, não se considera possível compreender a realidade de um país como o Brasil a partir da ideia de que todos os países possuem condições igualitárias de desenvolvimento no capitalismo. Deixando de lado classificações eufemísticas como as de países desenvolvidos e em desenvolvimento, utilizadas pelo Fundo Monetário Internacional (2008), Nações Unidas, entre outras, essa teoria afirma que o sistema capitalista, que só pode ser compreendido em sua totalidade, é regido por uma dialética da dependência (Marini, 1973). Nessa perspectiva, desenvolvimento e subdesenvolvimento, ou dependência, estão profundamente conectados, de modo que a dependência e subordinação dos países de capitalismo periférico são o outro lado da moeda do desenvolvimento dos países centrais. Desse modo, a inserção dos países periféricos na divisão internacional das economias capitalistas não estaria orientada para atingir seu próprio desenvolvimento ou independência:

Em outros termos, é a partir de então que se configura a dependência, entendida como uma relação de subordinação entre nações formalmente independentes, em cujo marco as relações de produção das nações subordinadas são modificadas ou recriadas para assegurar a reprodução ampliada da dependência. (Marini, 1973, p. 4)

Em sua obra Capitalismo dependente e classes sociais na América Latina (1973) Florestan Fernandes nega a pretensa universalidade do processo capitalista de desenvolvimento das classes sociais na Europa e passa a analisar a realidade sócio-histórica a partir de suas singularidades, sem, no entanto, desvinculá-la do contexto internacional. $\mathrm{O}$ que encontra a partir da análise histórica, estrutural e crítica empreendida é que a relação de subordinação dos países latino-americanos aos países de capitalismo central impossibilitou que as transformações sociais ocorressem conforme o esperado nas colônias recém-independentes. Segundo Fernandes (1973), as classes sociais na América Latina não se formaram como nos países europeus, e as principais razões para isso seriam justamente a relação de dependência e subordinação que é 
exercida, bem como a herança colonial e escravagista que, em vez de superada, foi atualizada e reaproveitada para a nova realidade social do continente e, portanto, no Brasil. Dessa forma, as classes dominantes internacionais são responsáveis por limitar e condicionar o desenvolvimento e a realidade social brasileira, em um processo que é intensificado pelo fato de que as classes dominantes no período colonial-escravagista não cederam lugar a uma nova classe essencialmente burguesa e industrial, mantendo então os mesmos dinamismos coloniais que lhes favoreciam no período anterior (Idem).

Nessa dinâmica, o desenvolvimento do capitalismo na América Latina conduz não ao antigo colonialismo e nem a um desenvolvimento autônomo como em outras partes do mundo, mas justamente a essa forma de dependência, inclusive levada pelas classes dominantes locais que se beneficiam disso e conseguem, nessa dinâmica do capitalismo dependente, tirar proveito, assim como as classes dominantes externas (Idem).

Mesmo sem explicitar e desenvolver de forma mais substancial os componentes raciais presentes nesse processo, a leitura de Florestan Fernandes possibilita ampliar a compreensão sobre a realidade racialmente estabelecida nesse processo em um país como o Brasil — o mais tardio das Américas a abolir oficialmente a escravidão. Nesse processo que combina - traduzido pela ideia de dependência - as raízes e a essência de um colonialismo abandonado formalmente com um capitalismo periférico, subalternizado na divisão econômica global, mas que, embora subdesenvolvido, resulta em intenso desenvolvimento restrito para as elites internacionais e nacionais. Duas elites que, embora separadas por habitarem países diferentes, estão intimamente relacionadas do ponto pelo aspecto racial que partilham.

Essa contradição que ao mesmo tempo distingue e unifica essas elites, e que é peça fundamental para a compreensão da dinâmica social de um país, embora seja muitas vezes desconsiderada, é um dos objetos de interesse da decolonialidade. Em "Colonialidade do poder, eurocentrismo e América Latina”, Aníbal Quijano busca evidenciar justamente a força da colonialidade nas relações de poder e afirma que "o processo de independência dos Estados na América Latina sem a descolonização da sociedade não pôde ser, 
não foi, um processo em direção ao desenvolvimento dos Estados-nação modernos, mas uma rearticulação da colonialidade do poder sobre novas bases institucionais" (2005, p. 123-124).

Para a decolonialidade, importa muito mais a dinâmica dos processos do que aquilo que é oficialmente estabelecido, como, por exemplo, o fim da escravidão negra e a independência do Brasil. O movimento teórico realizado por essa perspectiva é, ao mesmo tempo, de crítica às narrativas estabelecidas, geralmente produzidas pelo colonizador, e de elaboração e resgate de narrativas e epistemologias que partam de outros lugares, como, por exemplo, do chamado Sul global, ${ }^{12}$ e também por sujeitos que encarnam ou vivenciam essa experiência de subalternização/colonização, ainda que vivam no centro do centro do mundo.

Nesta perspectiva, é tarefa da maior importância a descentralização do poder de enunciação da verdade, de posse das colônias, e da pretensa universalização que estas sugerem (Bernardino-Costa e Grosfoguel, 2016). Do exercício realizado pela decolonialidade, contudo, emergem no centro das narrativas não apenas os territórios de países de lugares geográficos. Os sujeitos que as produzem também são objeto de preocupação. E no caso do debate racial, no qual historicamente o negro sempre foi muito tematizado, mas muito pouco escutado, o exercício de desconcentrar o poder de vocalização do sujeito clássico, branco e masculino é não apenas um esforço decolonial, mas, de fato, um esforço antirracista.

\section{Considerações finais}

A história do Brasil é marcada pela invasão colonial exploratória e pela escravidão racializada, que resultaram posteriormente num capitalismo tardio, periférico e estruturalmente racista. Diante do que foi discutido

12. O Sul global pode ser definido aqui como a referência que busca aglutinar países que se assemelham em sua condição de subalternidade para além da posição cartográfica que ocupam. 
neste artigo, fica evidente que, para compreender essa realidade são necessárias teorias que atentem para tais particularidades. É nesse sentido que se buscou aproximar e fazer dialogar as teorias da dependência e da decolonialidade.

É importante ressaltar que, mais do que explicar e descrever tais teorias, o exercício aqui proposto foi de apresentar a possibilidade de contribuição e convergência de cada uma delas, no contexto da interpretação das relações raciais no Brasil.

Além disso, o debate sobre genocídio e diáspora negra, aqui apresentado brevemente, objetiva acrescentar ao debate sobre questão racial a devida complexidade que possui e que é tão frequentemente ignorada em produções, debates e agendas institucionais sobre o assunto. Considerando que as políticas sociais na sociedade capitalista expressam embates e correlações de forças (Behring e Boschetti, 2006), faz-se importante que as formulações e estudos a respeito destas, numa perspectiva de totalidade, também incluam tensões raciais aqui apresentadas, além das de classe, gênero, sexualidade e outras. E tendo em vista o caráter crítico e socialmente comprometido das perspectivas teóricas aqui discutidas, faz-se importante afirmar que, se a realidade do agora é de opressão e exploração, que ela possa ser, então, mais do que compreendida. Que seja abolida e superada.

Recebido em 23/1/18 - Aprovado em 20/6/18

\section{Referências bibliográficas}

ALMEIDA, Magali da Silva. Desumanização da população negra: genocídio como princípio tácito do capitalismo. Em Pauta, Rio de Janeiro, v. 12, n. 34, 2015.

BERNARDINO, Joaze. Ação afirmativa e a rediscussão do mito da democracia racial no Brasil. Estudos Afro-Asiáticos 24, n. 2, p. 247-273, 2002. 
BERNARDINO-COSTA, Joaze; GROSFOGUEL, Ramón. Decolonialidade e perspectiva negra. Sociedade e Estado, Brasília, v. 31, n. 1, p. 15-24, 2016. Disponível em: <http:// www.scielo.br/scielo.php?script=sci_arttext\&pid=S0102-69922016000100015\&lng=e n\&nrm=iso $>$. Acesso em: 10 out. 2017.

BEHRING, Elaine Rossetti; BOSCHETTI, Ivanete. Política social: fundamentos e história. São Paulo: Cortez, 2006.

BRASIL. Câmara dos Deputados. Joaquim Nabuco. Perfis parlamentares, Brasília: Edições Câmara, 2010.

BURGINSKI, Vanda Micheli. O “novo” desenvolvimentismo da Cepal: contrarreforma do Estado, empregabilidade e redução de direitos no século XXI. 2016. Tese (Doutorado em Política Social) — Universidade de Brasília, Brasília, 2016.

CARCANHOLO, Marcelo Dias. O atual resgate crítico da teoria marxista da dependência. Trabalho, Educação e Saúde, Rio de Janeiro, v. 11, n. 1, p. 191-205, 2013.

FERNANDES, Florestan. Capitalismo dependente e classes sociais na América Latina. Rio de Janeiro: Zahar, 1973.

FLAUZINA, Ana Luiza Pinheiro. As fronteiras raciais do genocídio. Direito, Brasília, v. 1, n. 1, 2014.

FREYRE, Gilberto. Casa-grande \& senzala. 34 ed. Rio de Janeiro: Record, 1998.

GILROY, Paul. O Atlântico negro: modernidade e dupla consciência. 2. ed. São Paulo: Editora 34, 2012.

GUIMARÃES, Antônio Sérgio Alfredo. Classes, raças e democracia. São Paulo: Editora 34, 2002.

FMI - FUNDO MONETÁRIO INTERNACIONAL. Country Composition of WEO Groups. 2008. Disponível em: <http://www.imf.org/external/pubs/ft/weo/2006/01/data/ groups.htm\#1>Acesso em: 13 jan. 2018.

LUKACS, György. Introdução a uma estética marxista: sobre a categoria da particularidade. 2. ed. Rio de Janeiro: Civilização Brasileira, 1978.

MARINI, Ruy Mauro. A dialética da dependência. 10. ed. México: Editora Era, 1990 (1. ed., 1973). Tradução de Marcelo Carcanholo. Disponível em: https://www.marxists. org/portugues/marini/1973/mes/dialetica.htm. Acesso em: 13 jan. 2018.

MOURA, Clóvis. Rebeliões da senzala: quilombos, insurreições, guerrilhas. 5. ed. São Paulo: Anita Garibaldi; Fundação Maurício Grabois, 2014. 
NOGUEIRA, Oracy. Preconceito racial de marca e preconceito racial de origem: Sugestão de um quadro de referência para a interpretação do material sobre relações raciais no Brasil. Tempo Social, São Paulo, v. 19, n. 1, p. 287-308, 2007.

SANTOS, Gislene Aparecida dos. A invenção do "ser negro": um percurso das ideias que naturalizaram a inferioridade dos negros. São Paulo: Univ. Pontificia Comillas, 2002.

ORTEGAL, Leonardo. Raça, criminologia e sociologia da violência: contribuições a um debate necessário. Cadernos do CEAS, Salvador, n. 238, p. 527-542, 2016. Disponível em: $<$ https://cadernosdoceas.ucsal.br/index.php/cadernosdoceas/article/view/231>. Acesso em: 13 jan. 2018.

OXFAM Brasil. A distância que nos une: um retrato das desigualdades brasileiras. São Paulo, 2017. Disponível em: <https://www.oxfam.org.br/a-distancia-que-nos-une> Acesso em: 13 jan. 2018.

QUIJANO, Anibal. Colonialidade do poder, eurocentrismo e América Latina. In: LANDER, Edgardo (Org.). A colonialidade do saber: eurocentrismo e ciências sociais. Perspectivas latino-americanas. Buenos Aires: Clacso - Consejo Latinoamericano de Ciências Sociales, 2005.

SANTOS, Sales Augusto dos. A formação do mercado de trabalho livre em São Paulo: tensões raciais e marginalização social. Dissertação - Universidade de Brasília, Brasília, 1997.

TURRA, Cleusa; VENTURI, Gustavo. Racismo cordial: a mais completa análise sobre o preconceito de cor no Brasil. São Paulo: Ática, 1995.

WAISELFISZ, Julio J. Mapa da violência: os jovens do Brasil. Brasília: Garamond, 2014. WERNECK, Jurema. Racismo institucional e saúde da população negra. Saúde e Sociedade, v. 25, p. 535-549, 2016.

\section{Nota do autor}

Leonardo Ortegal - Assistente social, professor de Serviço Social, membro do Núcleo de Estudos Afro-Brasileiros da UnB.E-mail: ensejo@gmail.com 